\title{
Effectiveness of the Cussons Baby Sensicare Range of Products on Skin Moisturization, Softness and Suppleness of the Skin, Trans Epidermal Water Loss and Dermoprotection
}

\author{
Pepi D. Saputri, Yullya S. Mulyanti, Yuliarni, Busarin Kasemchainan, Partha P. Mitra, Paul Evans, \\ Haryono Hartono
}

R\&D Formulation, PZ Cussons Indonesia, Jakarta, Indonesia

Email: Pepi.Saputri@pzcussons.com

How to cite this paper: Saputri, P.D., Mulyanti, Y.S., Yuliarni, Kasemchainan, B., Mitra, P.P., Evans, P. and Hartono, H. (2019) Effectiveness of the Cussons Baby Sensicare Range of Products on Skin Moisturization, Softness and Suppleness of the Skin, Trans Epidermal Water Loss and Dermoprotection. Journal of Cosmetics, Dermatological Sciences and Applications, 9, 113-124.

https://doi.org/10.4236/jcdsa.2019.92010

Received: March 5, 2019

Accepted: May 26, 2019

Published: May 29, 2019

\section{Copyright $\odot 2019$ by author(s) and} Scientific Research Publishing Inc. This work is licensed under the Creative Commons Attribution International License (CC BY 4.0).

http://creativecommons.org/licenses/by/4.0/

(c) (i) Open Access

\begin{abstract}
OBJECTIVE: Baby skin differs significantly from adult skin and requires special care. The Cussons Baby Sensicare Range (Sensicare) of products has been specifically formulated for baby skin and a range of standard cosmetic clinical tests were conducted in adult females with dry skin to evaluate the effectiveness of the range on skin moisturization and barrier function. METHODS: The studies were within subject, controlled, single blind studies. For the Sensicare Body Wash skin moisturization (Corneometer) was measured before application and after 7 and 14 days of twice daily use. For the Sensicare Moisturizing Lotion and Sensicare Soothing Cream skin moisturization was measured before application and at 2, 4, 6, 8 and 24 hours after a single application; skin elasticity (Cutometer) and transepidermal water loss (TEWL, Tewameter) were assessed before and after 14 days of twice daily use; and skin erythema (Mexameter) before induction with sodium lauryl sulphate (SLS), and at 30 mins, 24 and 48 hours after patch removal. Changes from baseline and changes versus control were evaluated. RESULTS: Thirty to thirty-five subjects completed each study. Skin moisture content was significantly increased from baseline for all Cussons Baby Sensicare Products ( $\mathrm{p}<$ 0.05 for Hair \& Body Wash; and $p<0.001$ for Cream \& Lotion). Changes from baseline in skin elasticity were significantly superior to control (unperfumed liquid soap) after 14 days twice daily use of the Lotion, and Cream ( $\mathrm{p}<$ 0.05). There were no significant changes from baseline or significant differences from control in TEWL for the Lotion, or Cream. The increases in the average skin erythema index were significantly smaller for the Lotion, and Cream 30 minutes following SLS patch removal $(p<0.05$ v sterile water, $p<$ $0.001 \mathrm{v}$ no treatment for both products). All the Sensicare products were well
\end{abstract}


tolerated. CONCLUSION: These studies support the use of the Cussons Baby

Sensicare range of products for new born, sensitive and eczema prone skin.

\section{Keywords}

Moisturization, Skin Barrier, Skin Barrier Function, Skin

Physiology/Structure, Transepidermal Water Loss, Sensicare

\section{Introduction}

There are a number of key differences between newborn and adult skin which necessitate special care. In newborns and infants the epidermal barrier is not well developed for about the first 12 months following birth [1] making the skin delicate and sensitive. The principal component of the epidermal barrier is the stratum corneum which consists of keratinocytes embedded in a lipid matrix consisting of ceramides, cholesterol, and fatty acid [2]. In addition to reduced thickness of the stratum corneum in babies, the lipid content is also reduced. Further, there are differences in skin $\mathrm{pH}$; at birth the $\mathrm{pH}$ of the skin is $>6.0$ but following birth the acid mantle develops. The acid mantle plays an important role in protection against microorganisms [1]. Through disturbance of the epidermal barrier infant skin can become drier (there is greater transepidermal water loss in infants) and more prone to damage by allowing allergens and microbes to reach the dermis [2]. This can lead to inflammation characteristic of atopic dermatitis [3]. It is therefore important only to use skin care products on baby skin that, at least, maintain skin integrity, barrier function and protect against harmful agents.

The Cussons Baby Sensicare Range (PZ Cussons, Indonesia) is a new specially developed range of products for newborn, sensitive and eczema prone skin, developed with an understanding of the special characteristics of newborn skin. The products have been formulated to provide gentle cleansing while maintaining hydration and moisturization of the skin along with maintenance of the barrier function and acid mantle.

The Cussons Baby Sensicare Range of products is based on a Dermasoft $\mathrm{ft}^{\mathrm{tm}}$ Complex consisting of Avena sativa (oat) extract, Olea europaea (olive) fruit oil and ceramides. The topical use of avena sativa is well established and provides a variety of benefits including moisturization, barrier protection, and anti-inflammatory, antioxidant and soothing effects [4] leading to its use for a number of dermatological conditions [5] [6]. Olive oil's composition is similar to that of sebum; it contains oleic acid which acts as a skin softener and provides skin protection with its fat and antioxidant content [7]. Ceramides are natural lipids and are a major component in the stratum corneum. Decreased levels of ceramides disrupt the barrier function of the skin [8]. Replenishment of ceramides can enhance skin moisturization [9].

In addition to the key ingredients the Cussons Baby Sensicare Gentle Hair and 
Body Wash contains Arganiaspinosa (argan) kernal oil well known for its conditioning and shine enhancing effects and its use in dermocosmetology [10]. The Cussons Baby Sensicare 24 hr Daily Moisturizing Lotion and Cussons Baby Sensicare Intensive Soothing Cream also contain shea butter well known for its moisturizing effects and potent anti-inflammatory and antioxidant properties [11]. The $\mathrm{pH}$ of the products ranges from 4.5 - 6.0 to help maintain the optimal $\mathrm{pH}$ for baby skin.

In order to evaluate the effectiveness of the Cussons Baby Sensicare products on skin moisturization and barrier function a range of standard cosmetic clinical tests were conducted in adult females with dry skin by AssertraInnoMedikos Dermatology Laboratory in Indonesia (ISO 9001:2008 accredited). Studies were conducted in adults with dry skin as a surrogate for sensitive and atopic dermatitis (eczema) prone skin in babies.

\section{Methods}

\subsection{Objective}

Seven controlled healthy volunteer cosmetic studies of Cussons Baby Sensicare Gentle Hair and Body Wash (Hair and Body Wash), Cussons Baby Sensicare 24 hr Daily Moisturizing Lotion (Lotion) and Cussons Baby Sensicare Intensive Soothing Cream (Cream) (PZ Cussons, Indonesia) were conducted from April to June 2017 under the supervision of a Dermatologist. The study objectives are outlined below:

1) Skin Moisturization Studies AIM MMCT 52501, 52201 and 51901 (same subjects): Objective was to determine the mositurizing effect of each product as measured by a Corneometer.

2) Skin Barrier Function Studies AIM MXECT 52301 and 52001: Objective was to determine the skin elasticity as measured by a Cutometer and trans epidermal water loss (TEWL) as measured by a Tewameter of each product as an evaluation of the barrier function of the skin.

3) Dermoprotective Studies AIM MPCT 52401 and 52101 (same subjects): Objective was to determine the skin protection against acute irritation induced by SLS using a closed patch.

These were cosmetic studies conducted to local regulations. All subjects provided written informed consent to participate and the studies were conducted in consideration of the requirements of the Declaration of Helsinki and with the Principles of Good Clinical Practice (GCP).

\subsection{Test Product}

Commercially available product provided by PZ Cussons Indonesia was investigated in these studies. Cussons Baby Sensicare Gentle Hair and Body Washis a surfactant base with Dermasoft ${ }^{\text {th }}$ Complex and Argania spinosa (Argan) kernal oil. The Cussons Baby Sensicare $24 \mathrm{hr}$ Daily Moisturizing Lotion and Cussons Baby Sensicare Intensive Soothing Cream are oil in water emulsion with Der- 
masoft ${ }^{\text {tut }}$ Complex and Butyrospermum parkii (Shea) Butter. Detail of ingredients list of Cussons Baby Sensicare Range provided in Table 1.

\subsection{Study Subjects}

Healthy female Indonesian and Asian subjects, aged 18 - 55 years old with dry skin were required for each study. Subjects were recruited using a health questionnaire, interview and, if necessary, a dermatological examination. Subjects were excluded if they were pregnant or nursing; had any cutaneous pathology on the test area such as atopic dermatitis/eczema, psoriasis, and vitiligo; had used a medicine that could influence the study outcome within one week of study entry; were suffering from a serious or progressive disease or had participated in the cosmetic testing of products with the same benefit within one month of study entry.

Machin et al. [12] present extensive tables for reading off sample size, given typical values for the parameter used in calculating sample size (Table 2). Based on the table, the sample size required were 14, 22 dan 34 subjects per group for $p$ $<0.05, \mathrm{p}<0.01$ and $\mathrm{p}<0.001$ respectively. In these study 30 subjects $(\mathrm{n}=30)$ targeted to complete the study. Buffers were prepared to anticipate any dropouts. Detail subjects recruited and completed the study provided in Table 3, Table 4 and Table 5.

Table 1. Ingredients list cussons baby sensicare.

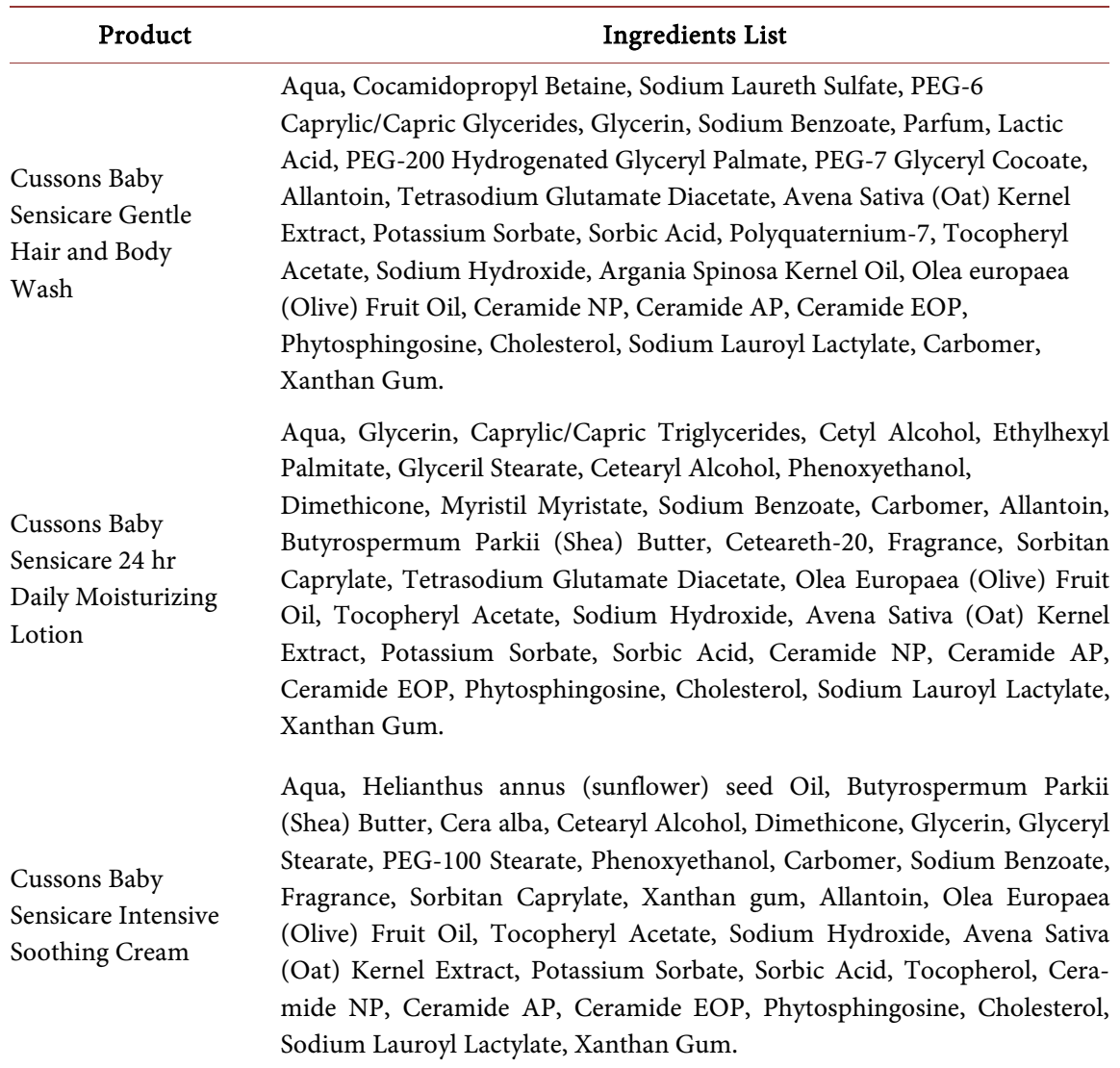


Table 2. Consequences for the sample size of changes in different parameters: one-tailed unpaired Student t-test. assuming the same standard deviation in the two groups.

\begin{tabular}{ccccccc}
\hline Change & Effect $^{*_{1}}$ & $\begin{array}{c}\text { Standard } \\
\text { deviation }\end{array}$ & $\begin{array}{c}\text { Effect } \\
\text { strength }^{*_{2}}\end{array}$ & $\mathrm{p}$ & Power & $\begin{array}{c}\text { Sample size } \\
\text { (per group) }\end{array}$ \\
\hline Effect & 5 & 5 & 1 & 0.025 & 0.8 & 17 \\
& 3 & 5 & 0.6 & 0.025 & 0.8 & 46 \\
& 1 & 5 & 0.2 & 0.025 & 0.8 & 401 \\
Standard Devia- & 5 & 5 & 0.1 & 0.025 & 0.8 & 1600 \\
tion & 5 & 25 & 0.2 & 0.025 & 0.8 & 401 \\
& 5 & 8 & 0.5 & 0.025 & 0.8 & 65 \\
& 5 & 3 & 0.625 & 0.025 & 0.8 & 42 \\
Level of Signi- & 5 & 5 & 1 & 0.05 & 0.8 & 7 \\
ficance & 5 & 5 & 1 & 0.01 & 0.8 & 22 \\
& 5 & 5 & 1 & 0.001 & 0.8 & 34 \\
& 5 & 5 & 1 & 0.025 & 0.95 & 27 \\
Power & 5 & 5 & 1 & 0.025 & 0.9 & 23 \\
& 5 & 5 & 1 & 0.025 & 0.7 & 14 \\
\hline
\end{tabular}

Table 3. Overview of cussons baby sensicare product application and observation period in the skin moisturization studies.

\begin{tabular}{|c|c|c|c|}
\hline Study & 52501 & 52201 & 51901 \\
\hline Product & Hair \& Body Wash & Lotion & Cream \\
\hline Product $\mathrm{pH}$ & $4.5-4.9$ & $5.5-6.0$ & $5.0-5.8$ \\
\hline NRecruited:Completed & 40:35 & \multicolumn{2}{|c|}{$33: 32$} \\
\hline Average Age (years) & 32.2 (range $18-52$ ) & \multicolumn{2}{|c|}{38 (range $21-52$ ) } \\
\hline$\%$ Female & \multicolumn{3}{|c|}{100} \\
\hline Amount of Product & $\pm 0.64 \mathrm{~g} /$ application & $\pm 0.06 \mathrm{mg} / 16 \mathrm{~cm}^{2}$ & $\pm 0.04 \mathrm{mg} / 16 \mathrm{~cm}^{2}$ \\
\hline Frequency & Twice a day & \multicolumn{2}{|c|}{ Once } \\
\hline How to use & $\begin{array}{l}\text { Apply and lather to } \\
\text { forearm and forehead, } \\
\text { rinse well }\end{array}$ & \multicolumn{2}{|c|}{$\begin{array}{l}\text { Apply onto tested } \\
\text { area and dry skin }\end{array}$} \\
\hline Period of observation & $\begin{array}{c}\text { Pre and after } 7 \text { and } 14 \\
\text { days use }\end{array}$ & \multicolumn{2}{|c|}{$\begin{array}{c}\text { Pre and post use at } 2,4,6,8 \text { and } 24 \\
\text { hours after application }\end{array}$} \\
\hline Tested Area & $\begin{array}{l}\text { Randomised left or right } \\
\text { forearm and face skin }\end{array}$ & \multicolumn{2}{|c|}{$\begin{array}{l}\text { Randomised left or } \\
\text { right forearm skin }\end{array}$} \\
\hline Control & \multicolumn{3}{|c|}{ No treatment } \\
\hline \multicolumn{4}{|c|}{ Self-Evaluation for Sensory Analysis } \\
\hline Amount of Product & $\pm 2.69 \mathrm{~g} /$ application & \multirow{4}{*}{\multicolumn{2}{|c|}{ Not Done }} \\
\hline Frequency & Three times a week & & \\
\hline How to use & $\begin{array}{l}\text { Apply and lather to hair, } \\
\text { rinse well }\end{array}$ & & \\
\hline Period of observation & $\begin{array}{l}\text { Pre and after } 7 \text { and } 14 \\
\text { days use }\end{array}$ & & \\
\hline Tested Area & On the hair & & \\
\hline
\end{tabular}


Table 4. Overview of cussons baby sensicare product application and observation period for skin barrier function study.

\begin{tabular}{|c|c|c|}
\hline Study & AIM MXECT 52301 & AIM MXECT 52001 \\
\hline Product & $\begin{array}{c}24 \text { hours Daily } \\
\text { Moisturizing Lotion }\end{array}$ & $\begin{array}{c}\text { Intensive } \\
\text { Soothing Cream }\end{array}$ \\
\hline N Recruited:Completed & $31: 30$ & $33: 30$ \\
\hline Average Age (years) & 37.9 (range $21-52$ ) & 32 (range $17-50)$ \\
\hline$\%$ Female & \multicolumn{2}{|c|}{100} \\
\hline \multicolumn{3}{|c|}{ Test for Increasing Skin Elasticity ${ }^{1}$ and Trans Epidermal Water Loss ${ }^{2}$} \\
\hline Amount of Product & $\pm 0.47 \mathrm{~g} /$ application & $\pm 0.28 \mathrm{~g} /$ application \\
\hline Frequency & \multicolumn{2}{|c|}{ Twice a day } \\
\hline How to use & \multicolumn{2}{|c|}{ Apply onto body and dry skin } \\
\hline Period of observation & \multicolumn{2}{|c|}{ Pre and after 14 days use } \\
\hline Tested Area & \multicolumn{2}{|c|}{ Randomised left or right forearm } \\
\hline Control & \multicolumn{2}{|c|}{ Unperfumed liquid soap } \\
\hline \multicolumn{3}{|c|}{ Self-Evaluation for Sensory Analysis } \\
\hline Amount of Product & $\begin{array}{l} \pm 0.47 \mathrm{~g} / \text { application to forearm } \\
\quad \pm 0.34 \mathrm{~g} / \text { application to face }\end{array}$ & $\begin{array}{c} \pm 0.28 \mathrm{~g} / \text { application to forearm } \\
\pm 0.21 \mathrm{~g} / \text { application to face }\end{array}$ \\
\hline Frequency & \multicolumn{2}{|c|}{ Twice a day, morning and night } \\
\hline How to use & \multicolumn{2}{|c|}{ Apply onto body and dry skin } \\
\hline Period of observation & \multicolumn{2}{|c|}{ Pre and after 14 days use } \\
\hline Tested Area & \multicolumn{2}{|c|}{ Left or right forearm and face skin } \\
\hline Control & \multicolumn{2}{|c|}{ Unperfumed liquid soap } \\
\hline
\end{tabular}

Table 5. Overview of cussons baby sensicare product application and observation period for dermoprotection studies.

\begin{tabular}{|c|c|c|}
\hline Study & AIM MPCT 52401 & AIM MPCT 52101 \\
\hline Product & $\begin{array}{l}24 \text { hours Daily } \\
\text { Moisturizing Lotion }\end{array}$ & $\begin{array}{c}\text { Intensive } \\
\text { Soothing Cream }\end{array}$ \\
\hline N Recruited:Completed & \multicolumn{2}{|c|}{$33: 33$} \\
\hline Average Age (years) & \multicolumn{2}{|c|}{33.3 (range $18-50$ ) } \\
\hline$\%$ Female & \multicolumn{2}{|c|}{100} \\
\hline \multicolumn{3}{|c|}{ Test for Assessing Dermoprotective Properties ${ }^{1}$} \\
\hline Amount of Product & \pm 0.09 gram/application & \pm 0.07 gram/application \\
\hline Frequency & \multicolumn{2}{|c|}{ Twice a day for 7 days } \\
\hline How to use & \multicolumn{2}{|c|}{ Apply onto body and dry skin } \\
\hline Period of observation & \multicolumn{2}{|c|}{$\begin{array}{l}\text { Before induction with SLS, at } 30 \text { mins, } \\
24 \text { and } 48 \text { hours after patch removal }\end{array}$} \\
\hline Tested Area & \multicolumn{2}{|c|}{ Randomised left or right upper arm } \\
\hline Control & \multicolumn{2}{|c|}{$\begin{array}{l}\text { Sterile Water } \\
\text { No Treatment }\end{array}$} \\
\hline
\end{tabular}




\subsection{Trial Design}

The studies were within subject, controlled, single blind studies (the investigator did not know the application location of the test and control products). There was a 5 - 7 day washout period during which subjects were asked not to use any skin care products that had the same or similar function as the tested products on the designated test areas. During the studies subjects could only use the tested products provided by the investigator at the related tested areas. On study days no products were used. Prior to the study measurements being taken, subjects spent $10-20$ minutes in an acclimatization room with the skin area to be measured uncovered.

Skin moisture content was measured using a Corneometer ${ }^{\circledR}$ CM825; skin elasticity was measured using a Cutometer ${ }^{\circledR}$ MPA580; trans epidermal water loss was measured using a Tewameter ${ }^{\oplus}$ TM300 (opened chamber); and skin erythema index was measured using a Mexameter ${ }^{\circledR}$ MX18. At each observation point in all studies, 3 measurements were taken. Overviews of the product application and observation periods are summarised in Table 3 for the skin moisturization dies and Table 4 for the skin barrier function and Table 5 for dermoprotection studies.

\section{Skin Moisturization Studies}

For the Hair \& Body Wash Corneometer ${ }^{\circledR}$ CM825 measurements were taken pre product application and after 7 and 14 days of twice daily use. For each application \pm 0.64 grams was applied to a randomised area of the forearm and forehead, lathed and rinsed well. In addition, three times a week for two weeks \pm $2.69 \mathrm{~g} /$ application was applied to the hair, lathed and rinsed well for subject sensory evaluations at 7 and 14 days. For the Lotion and the Cream Corneometer ${ }^{\circledR}$ CM825 measurements were taken pre product application and at 2, 4, 6, 8 and 24 hours after application of a single application (once in the morning). The applications consisted of $\pm 0.06 \mathrm{~g} / 16 \mathrm{~cm}^{2}$ of the Lotion and $\pm 0.04 \mathrm{~g} / 16 \mathrm{~cm}^{2}$ of the Cream.

\section{Skin Barrier Function Studies}

For the Lotion and Cream Cutometer ${ }^{\circledR}$ MPA580 and Tewameter ${ }^{\circledR}$ TM300 measurements were taken pre product application and after twice daily product application for 14 days. The applications consisted of $\pm 0.47 \mathrm{~g} /$ application of the Lotion and $\pm 0.28 \mathrm{~g}$ /application of the Cream to a randomised area of the left or right forearm. In addition $\pm 0.34 \mathrm{~g}$ /application of the Lotion and 0.21 g/application of the Cream were applied twice a day to the face. Subjects completed self-evaluation questionnaires for sensory analysis after 7 and 14 days of product use.

\section{Dermoprotection Studies}

In the dermoprotective studies, product (Lotion or Cream) was applied twice daily to the upper arm for 7 days. Acute irritation was induced with $20 \mu \mathrm{l}$ SLS in a Finn Chamber patch applied to the test area for 24 hours. Mexameter ${ }^{\circledR}$ MX18 measurements for skin erythema index were taken after 7 day product applica- 
tion but before irritation induction with SLS, and at 30 mins, 24 and 48 hours after patch removal. The applications consisted of $\pm 0.09 \mathrm{~g} /$ application of the lotion and $\pm 0.07 \mathrm{~g} /$ application of the cream to a randomised area of the left or right upper arm.

\subsection{Evaluation and Analysis}

The averaged measurements for the 3 meter readings were analysed by Student $\mathrm{T}$ Test; both absolute values post application versus baseline and changes from pre product application versus control were evaluated.

\section{Results}

\section{Skin Moisturization}

Skin Moisturization: Forty female subjects were recruited into study 52501, there were five dropouts with thirty-five subjects completing the study. The average age of the subjects was 32.2 years (range 18 - 52 years). Changes from baseline in skin moisture content are summarised in Table 6. Skin moisture content was significantly increased from baseline after 7 and 14 days twice daily use of the Hair \& Body Wash on the skin of the forearm ( $p<0.01$ and $p<0.05$ respectively) and forehead ( $<<0.001)$. Changes from baseline were significantly superior to control (no treatment) after 14 days use on the forearm $(\mathrm{p}<0.05)$ and after 7 and 14 days use on the forehead $(\mathrm{p}<0.05)$. Positive endorsement of the Hair \& Body Wash was demonstrated from the self-evaluation questionnaires, the most positive responses (32/35 subjects) after 14 days use were; subjects stated that their hair was easy to comb, that their scalp/skin became moist and the product was mild on their scalp.

Thirty-three female subjects were recruited into studies 52201 and 51901, there was one dropout with thirty-two subjects completing the study. The average age of the subjects was 38 years (range 21 - 52 years). Changes from baseline in skin moisture content are summarised in Table 7. Skin moisture content was significantly increased from baseline after 2, 4, 6, 8 and 24 hours after an application of the Lotion, and the Cream to skin on the forearm $(p<0.001)$. Changes from baseline were significantly superior to control (no treatment) after 2, 4, 6, 8 and 24 hours after application of each Sensicare product $(\mathrm{p}<0.001)$.

\section{Skin Barrier Function}

Skin Elasticity and TEWL: Thirty-one subjects were recruited into study 52301, there was one dropout with thirty subjects completing the study. The average age of the subjects was 37.9 years (range 21 - 52 years). Thirty-three subjects were recruited into study 52001, there was three dropouts with thirty subjects completing the study. The average age of the subjects was 32 years (range 17 - 50 years). Changes from pre-application in both studies are summarized in Table 8. Skin elasticity was significantly increased from baseline after application of the Lotion, and the Cream to skin on the forearm $(\mathrm{p}<0.001$ and $\mathrm{p}<0.05$ respectively). Changes from baseline were significantly superior to control (un- 
perfumed liquid soap) after 14 days $(\mathrm{p}<0.05)$. There were no significant changes from baseline or significant differences from control in TEWL for either the Lotion or the Cream. From the self-evaluation questionnaires all the subjects using the Lotion (30/30) felt their skin was soft and supple, their skin felt smooth, and their skin looked healthy on both their forearm and their face after 14 days twice daily use. This was markedly different to the control group (unperfumed liquid soap) particularly with respect to the face skin where no more than 2 subjects reported any positive cosmetic effects. From the self-evaluation questionnaires the most positive responses for the subjects using the Cream (28/30) were that they felt their skin was soft and supple and their skin felt smooth on both their forearm and their face after 14 days twice daily use. In addition all subjects felt the skin on their forearm felt instantly moist. This was markedly different to the control group (unperfumed liquid soap) particularly with respect to the face skin where no more than 4 subjects reported any positive cosmetic effects.

\section{Dermoprotection}

Dermoprotection: Thirty-three subjects were recruited into studies 52401 and 52101, there were no dropouts with all thirty-three subjects completing the study. The average age of the subjects was 33.3 years (range 18 - 50 years). Skin erythema index results are summarized in Table 9. The increases in the average skin erythema index were significantly smaller for the Lotion, and the Cream 30 minutes following SLS patch removal ( $p<0.05 \mathrm{v}$ sterile water, $\mathrm{p}<0.001 \mathrm{v}$ no treatment for both products). This shows that both the lotion and cream provide protective layer onto the skin, hence preventing skin erythema. It suggests that regular application of the lotion and/or cream is recommended to continue providing moisture and protection for our subjects' dry skin. There were no significant differences in the skin erythema index 24 and 48 hours post SLS patch removal. Although that means the skin of healthy panelists can recover by itself after certain period of time, as suggested above application of the lotion and/or cream regularly will help to protect the skin from external irritants.

Table 6. Change in skin moisture content following application of cussons baby sensicare gentle hair \& body wash $(\mathrm{n}=35)$.

\begin{tabular}{ccccc}
\hline & \multicolumn{2}{c}{$\begin{array}{c}\text { Change in Skin } \\
\text { Moisture Content (Unit) }\end{array}$} & \multicolumn{2}{c}{$\begin{array}{c}\text { Significance v } \\
\text { Control }\end{array}$} \\
\cline { 2 - 6 } & $\Delta$ T7-T0 & $\Delta$ T14-T0 & T7 & T14 \\
\hline $\begin{array}{c}\text { Sensicare Hair \& } \\
\text { Body Wash } \\
\text { Control }\end{array}$ & $2.44 \pm 0.93$ & $1.53 \pm 0.92$ & ns & $\mathrm{p}<0.05$ \\
$\begin{array}{c}\text { Sensicare Hair \& } \\
\text { Body Wash } \\
\text { Control }\end{array}$ & $2.38 \pm 0.70$ & $0.12 \pm 0.81$ & & \\
& $12.23 \pm 2.40$ & $5.68 \pm 1.53$ & $\mathrm{p}<0.05$ & $\mathrm{p}<0.05$ \\
& $8.49 \pm 2.47$ & $1.61 \pm 2.25$ & & \\
\hline
\end{tabular}

Skin moisture content measured by Corneometer ${ }^{\oplus}$ CM825; T0 = before tested product application; T7, T14 $=$ after twice daily product application for 7 days and 14 days; $\Delta=$ change. Control $=$ no treatment. 
Table 7. Change in skin moisture content following application of cussons baby sensicare 24 hours daily moisturizing lotion and intensive soothing cream $(\mathrm{n}=32)$.

\begin{tabular}{cccccc}
\hline \multirow{2}{*}{ Product } & \multicolumn{5}{c}{ Change in Skin Moisture Content (Unit) } \\
\cline { 2 - 6 } & $\Delta$ T2-T0 & \multicolumn{1}{c}{$\Delta$ T4-T0 } & $\Delta$ T6-T0 & $\Delta$ T8-T0 & $\Delta$ T24-T0 \\
\hline Lotion & $14.98 \pm 0.96^{*}$ & $19.88 \pm 1.39^{*}$ & $25.07 \pm 1.38^{*}$ & $17.29 \pm 1.56^{*}$ & $19.84 \pm 1.10^{*}$ \\
Control & $3.41 \pm 0.65$ & $5.59 \pm 0.79$ & $3.64 \pm 0.83$ & $2.17 \pm 0.82$ & $6.23 \pm 0.95$ \\
Cream & $12.34 \pm 1.00^{*}$ & $17.50 \pm 1.16^{*}$ & $20.22 \pm 1.25^{*}$ & $15.48 \pm 1.72^{*}$ & $15.66 \pm 1.30^{*}$ \\
Control & $1.78 \pm 0.94$ & $1.97 \pm 0.59$ & $2.14 \pm 0.66$ & $0.80 \pm 1.05$ & $3.47 \pm 1.02$ \\
\hline
\end{tabular}

Skin moisture content measured by Corneometer ${ }^{\circ} \mathrm{CM} 825 ; \mathrm{T} 0=$ before tested product application; $\mathrm{T} 2, \mathrm{~T} 4$, T6, T8, T24 = hours after application; $\Delta=$ change; Control $=$ no treatment; ${ }^{*}$ significant defferent $\mathrm{p}<0.001$ $\mathrm{v}$ control for change in skin moisture, Student $\mathrm{T}$ Test.

Table 8. Change in skin elasticity and TEWL following application of cussons baby sensicare 24 hours daily moisturizing lotion $(n=30)$ and intensive soothing cream $(n=30)$.

\begin{tabular}{ccccc}
\hline \multirow{2}{*}{ Product } & \multicolumn{2}{c}{ Skin Elasticity } & \multicolumn{2}{c}{ TEWL } \\
\cline { 2 - 5 } & $\begin{array}{c}\text { Change in Skin } \\
\text { Elasticity (unit) }\end{array}$ & $\begin{array}{c}\text { Significance } \mathrm{v} \\
\text { Control }\end{array}$ & $\begin{array}{c}\text { Change in TEWL } \\
\left(\mathrm{g} / \mathrm{hm}^{2}\right)\end{array}$ & $\begin{array}{c}\text { Significance } \mathbf{~} \\
\text { Control }\end{array}$ \\
\cline { 2 - 5 } & $\Delta \mathrm{T} 14-\mathrm{T} 0$ & $\mathrm{~T} 14$ & $\Delta \mathrm{T} 14-\mathrm{T} 0$ & $\mathrm{~T} 14$ \\
\hline Lotion & $0.0688 \pm 0.0170$ & $\mathrm{P}<0.05$ & $2.26 \pm 0.79$ & $\mathrm{~ns}$ \\
Control & $0.0265 \pm 0.0161$ & & $1.97 \pm 0.73$ & \\
Cream & $0.0392 \pm 0.0200$ & $\mathrm{P}<0.05$ & $-0.57 \pm 1.28$ & $\mathrm{~ns}$ \\
Control & $-0.0075 \pm 0.0125$ & & $0.89 \pm 0.93$ & \\
\hline
\end{tabular}

Skin elasticity measured by Cutometer ${ }^{\oplus}$ MPA580; TEWL measured by Tewameter ${ }^{\circledast}$ TM300; T0 = before tested product application; $\mathrm{T} 14=$ after twice daily product application for 14 days; $\Delta=$ change; Control = unperfumed liquid soap; $\mathrm{ns}=$ not significant.

Table 9. Change in the skin erythema index following application of cussons baby sensicare 24 hours daily moisturizing lotion and intensive soothing cream $(\mathrm{n}=33)$ after induction with SLS 24 hour patch.

\begin{tabular}{cccc}
\hline \multirow{2}{*}{ Product Applied } & \multicolumn{3}{c}{ Change from T0 in Skin Erythema Index (unit) } \\
\cline { 2 - 4 } & T30 m & T24 h & T48 h \\
\hline Lotion & $7.1 \pm 5.3^{1}$ & $44.1 \pm 7.5$ & $37.3 \pm 6.4$ \\
Cream & $9.7 \pm 4.4^{1}$ & $50.1 \pm 7.1$ & $40.7 \pm 10.2$ \\
Sterile Water & $29.3 \pm 7.3$ & $46.4 \pm 6.4$ & $47.5 \pm 6.8$ \\
No Treatment & $32.2 \pm 7.2$ & $49.6 \pm 9.9$ & $39.7 \pm 7.9$ \\
\hline
\end{tabular}

${ }^{1} \mathrm{p}<0.05 \mathrm{v}$ sterile water, $\mathrm{p}<0.001 \mathrm{v}$ no treatment.

There were no adverse events reported in the studies and all the Sensicare products were well tolerated. From the subject sensory questionnaires in 52501, $2 / 35$ subjects and $1 / 35$ subjects said their scalp felt itchy after 7 and 14 days respectively; $1 / 35$ subjects and 0/35 subjects said they felt a stinging sensation of their scalp after 7 and 14 days respectively of three times a week use of the Hair \& Body Wash. There were no reports of any burning sensations with the Hair \& 
Body Wash. From the subject sensory questionnaires in 52301 there were no reports of itchy skin or a burning sensation on the skin of the forearm and face, or a stinging sensation on the face after 14 days twice daily use of the Lotion. From the subject sensory questionnaires in 52001 there were no reports of itchy skin on the forearm, 1/30 reported their face skin felt itchy, $3 / 30$ reported they felt a burning sensation on their forearm and face, and 2/30 felt a stinging sensation on the their face skin after 14 days twice daily use of the Cream.

\section{Discussion}

These studies utilised standard cosmetic testing methodologies with sufficient numbers of participants. Adult females with dry skin were selected as it is Cussons policy not to test products on babies but rather test all products in clinical studies on adult skin including those with sensitive and eczema prone skin. Under the standard cosmetic testing conditions, all the products were shown to increase the skin moisture content on adult dry skin better than control (no product). Different approaches were taken for the application of the different products to reflect their intended use. The Hair \& Body Wash was applied to the skin of the forearm and forehead for 14 days whereas the Lotion, and the Cream products were applied only once to the forearm. In all cases there were significant improvements from baseline and significant differences over the control (no treatment) demonstrating the moisturizing properties of the Sensicare product range.

The Lotion, and the Cream were shown to maintain the skin barrier function. Skin elasticity was significantly improved compared with unperfumed liquid soap after twice daily use for 14 days of each product. However, there were no reductions in TEWL or differences from control (unperfumed liquid soap) in TEWL after 14 days twice daily use of the Sensicare Lotion, and Cream.

Pre-application of the Lotion, and the Cream twice daily for 7 days had the potency to protect against early skin erythema induced by SLS on adults with dry skin. Dermoprotection is very important for babies who have dry or sensitive skin as it is very easy for these types of skin to become irritated.

As well as objective measures it is important to gather subjective views on the effects of cosmetic products. This was achieved via the administration of the self-evaluation questionnaires. Overwhelmingly positive responses were received for statements concerning mositurization and soft and supple skin/hair feel. These positive responses for the Sensicare products were markedly different to those achieved for the controls. Further negative views of sensations such as itchy, burning, and stinging were limited. All the products were very well tolerated.

\section{Conclusion}

In conclusion, these studies support the use of the Cussons Baby Sensicare range of products for new born, sensitive and eczema prone skin by providing gentle cleansing with adequate hydration and moisturization of the skin while main- 
taining the barrier function of the skin.

\section{Acknowledgements}

Research was funded by PZ Cussons, Indonesia.

\section{Conflicts of Interest}

The authors declare no conflicts of interest regarding the publication of this paper.

\section{References}

[1] Fernandes, J.D., Machado, M.C. and Oliveira, N.Z. (2011) Children and Newborn Skin Care and Prevention. Anais Brasileiros de Dermatologia, 86, 102-110.

[2] Sarkar, R., Basu, S., Agrawal, R.K., et al. (2010) Skin Care for the Newborn. Indian Pediatrics, 47, 593-598. https://doi.org/10.1007/s13312-010-0132-0

[3] Cork, M.J., Robinson, D.A., Vasilopoulos, Y., et al. (2006) New Perspectives on Epidermal Barrier Dysfunction in Atopic Dermatitis: Gene-Environment Interactions. Journal of Allergy and Clinical Immunology, 118, 3-21. https://doi.org/10.1016/j.jaci.2006.04.042

[4] Nebus, J., Nollent, V. and Wallo, W. (2012) New Learnings on the Clinical Benefits of Colloidal Oatmeal in Atopic Dermatitis. Supplement to the Dermatologist October.

[5] Pazyar, N., Yaghoobi, R., Kazerouni, A., et al. (2012) Oatmeal in Dermatology: A Brief Review. Indian Journal of Dermatology, Venereology and Leprology, 78, 142-145. https://doi.org/10.4103/0378-6323.93629

[6] Zari, S.T. and Zari, T.A. (2015) A Review of Four Common Medicinal Plants Used to Treat Eczema. Journal of. Medicinal Plants Research, 9, 702-711. https://doi.org/10.5897/jmpr2015.5831

[7] Viola, P. and Viola, M. (2009) Virgin Olive Oil as a Fundamental Nutritional Component and Skin Protector. Clinics in Dermatology, 27, 159-165. https://doi.org/10.1016/j.clindermatol.2008.01.008

[8] Imokawa, G. and Ishida, K. (2014) Role of Ceramide in the Barrier Function of the Stratum Corneum: Implications for the Pathogenesis of Atopic Dermatitis. Journal of Clinical \& Experimental Dermatology Research, 5, 206. https://doi.org/10.4172/2155-9554.1000206

[9] Wollenweber, U. and Farwick, M. (2006) Application of skin-Identical Ceramide 3 for Enhance Skin Moisturization and Smoothness: Latest Results. Euro Cosmetics. Special Issue 1-5.

[10] Guillaume, D. and Charrouf, Z. (2011) Argan Oil and Other Arganproducts: Use in Dermocosmetology. European Journal of Lipid Science and Technology, 113, 403-408. https://doi.org/10.1002/ejlt.201000417

[11] Lin, T.K., Zhong, L. and Santiago, J.L. (2018) Anti-Inflammatory and Skin Barrier Repair Effects of Topical Application of Some Plant Oils. International Journal of Molecular Sciences, 19, pii: E70. https://doi.org/10.3390/ijms19010070

[12] Machin, D., Campbell, M.J., Fayers, P.M. and Pinol, A.P.Y. (1987) Sample Size Tables for Clinical Studies. 2nd Edition, Blackwell Science Ltd., Oxford, London, Berlin, 1-315.

https://doi.org/10.1002/(sici)1097-0258(19990228)18:4<494::aid-sim56>3.0.co;2-t 